\title{
Os arquivos pessoais e a história da ciência: a ornitologia brasileira no arquivo de Helmut Sick
}

\section{The personal archives and the history of science: the Brazilian ornithology at the Helmut Sick archives}

\author{
Douglas Vieira Machado \\ Programa de Capacitação Institucional (PCI), Museu de Astronomia e Ciências Afinns \\ (MAST) \\ douglasmachado@mast.br \\ https://orcid.org/0000-0001-6970-8670 \\ Maria Celina Soares de Mello e Silva \\ Programa de Pós-Graduação em Preservação de Acervos de C\&T, \\ Museu de Astronomia e Ciências Afins (MAST/MCTIC) \\ celina@mast.br \\ https://orcid.org/0000-0003-1322-7549
}

\begin{abstract}
Resumo: O presente trabalho busca analisar e demonstrar questões relativas ao tratamento e organização Arquivo Helmut Sick, sob guarda do Museu de Astronomia e Ciências Afins. Por meio dos resultados parciais obtidos na identificação tipológica buscamos evidenciar a importância da organização de arquivos pessoais de cientistas para a História da Ciência, tendo como estudo o arquivo de Helmut Sick, e como fonte de pesquisa para entre outras áreas, como a Arquivologia e a Ornitologia.
\end{abstract}

Palavras-chave: História da ciência. Ornitologia. Arquivos pessoais. Tipologia documental. Identificação de documentos.

Abstract: The present work seeks to analyze and demonstrate issues related to the treatment and organization of Helmut Sick Archive, under the custody of the Museum of Astronomy and Related Sciences. Through the partial results obtained in typological identification we seek to highlight the importance of the organization of personal archives of scientists for the History of Science, having 
as study the Helmut Sick archive, and as a source of research for among other areas, such as Archival Sciences and Ornithology.

Keywords: History of science. Ornithology. Personal archives. Document typology. Typological identification.

Recebido: 01/10/2017 Aceito: 27/10/2017 Publicado: 06/11/2017

\section{Introdução}

Os arquivos pessoais durante muito tempo foram negligenciados e colocados à margem do saber arquivístico, em um limbo onde em detrimento dos arquivos oficiais, nem eram considerados arquivos de fato. Contudo, atualmente gozam de prestígio por parte da Arquivologia, constituindo uma importante fonte de pesquisa equiparável (ou complementar) aos arquivos institucionais. Livres dos mecanismos que condicionam a acumulação institucional, a constituição dos arquivos pessoais é pautada pela vontade de seu titular (SILVA, 2015). Se nos arquivos de organismos jurídicos é possível observar, entre outras, relações políticas, legais ou econômicas, em um arquivo pessoal pode-se ir mais além, uma vez que os documentos íntimos expressam não só as relações entre o indivíduo e Estado, mas também as relações entre o indivíduo e instituições e o indivíduo e a sociedade. Neste sentido, o objetivo deste trabalho é o de procurar divulgar a pesquisa realizada no arquivo Helmut Sick sobre identificação de documentos por meio de estudo tipológico, fruto do projeto "Estudo da espécie e tipologia documental de arquivos de ciência e tecnologia", coordenado pelo Arquivo de História da Ciência do Museu de Astronomia e Ciências Afins (MAST). O objetivo da pesquisa é refletir sobre a metodologia de identificação tipológica como ferramenta a favor de arquivistas e pesquisadores para o reconhecimento e a contextualização dos documentos de um arquivo e, principalmente, auxiliar no processo de organização.

\section{Identificação de documentos por meio de estudo tipológico}

Iniciado em 2013, o projeto tem como objetivo o estudo da tipologia da produção documental arquivística oriunda das atividades de pesquisa de instituições científicas, visando a elaboração de procedimentos, recomendações e políticas de preservação, com foco no estudo da produção documental arquivística dos laboratórios científicos e tecnológicos no âmbito do Ministério da Ciência, Tecnologia, Inovações e Comunicações (MCTIC).

A fase atual tem como objeto de estudo os arquivos pessoais de cientistas sob a guarda do MAST, como o arquivo do antropólogo Luiz de Castro Faria. No âmbito do projeto já foram realizados o levantamento tipológico nos arquivos de Bernhard Gross e Joaquim da Costa Ribeiro. Apresentamos aqui o estudo de identificação tipológico em realização, tendo como objeto o arquivo do ornitólogo Helmut Sick.

$\mathrm{O}$ arquivo já tem sido objeto de pesquisa, mesmo que ainda esteja em processo de organização. Uma vez que o arquivo pessoal encontra-se inteiro no MAST, o presente 
estudo, portanto, visa ampliar o conhecimento sobre o produtor e sua obra, de forma que as atividades sejam mapeadas e proporcionem contexto para a organização do arquivo. Desta forma, este arquivo poderá se tornar fonte de pesquisa para, entre outras áreas, a historiografia, a arquivologia e a ornitologia. Em um âmbito mais específico, após sua organização, o arquivo poderá tornar-se fonte para a história da ciência, que busca nos arquivos pessoais, fatos e informações que complementem as fontes oficiais e que, eventualmente, possa fornecer um conhecimento voltado para a personalidade, a vida cotidiana e familiar do cientista em seu campo de atuação, e até mesmo a vida profissional, sob outro ponto de vista, que não o oficial.

A pesquisa almeja estudar as espécies e tipos documentais do Arquivo Helmut Sick visando a organização do acervo, de forma a promover o acesso a este patrimônio da ciência brasileira, tornando-o fonte de pesquisa para a história da ciência. Os objetivos da pesquisa podem ser resumidos em três âmbitos: a identificação dos documentos; o tratamento do arquivo, com sua organização, produção de instrumentos de pesquisa, digitalização e alimentação na base de dados Zenith; e a difusão, por meio da produção de artigos e apresentação de comunicações em eventos, como também, a disseminação do conhecimento produzido sobre o acervo e sobre arquivos pessoais, e dessa forma, servindo de fonte de pesquisa para historiadores, ornitólogos dentre outros possíveis interessados. Também objetivamos que os dados sobre o processo de tratamento e a metodologia empregada no tratamento deste arquivo sejam utilizados por outros projetos, institucionais ou exteriores, e fomentem a melhoria da qualidade de atuais ou novas pesquisas no campo da Arquivologia.

\section{Helmut Sick e seu Arquivo}

Heinrich Maximilian Friedrich Helmut Sick nasceu em 10 de janeiro de 1910, em Leipzig, Alemanha. Estudou ciências naturais nas universidades de Koenigsberg, Munique, Leipzig e Berlim. Em 1937 obteve o título de Doutor em Filosofia pela Faculdade de Matemática e Ciências da Universidade Friedrich Wilhelm de Berlim, com a tese "A estrutura microscópica da pena da ave e sua função".

Em 1939, viajou ao Brasil em expedição organizada e patrocinada pelo Museu Zoológico da Universidade de Berlim, em convênio com o Museu Nacional do Rio de Janeiro, para realizar pesquisas ornitológicas, com o objetivo de coletar material ornitológico e estudar espécies raras, como o mutum Crax blumenbachii e o jacu-deestalo Neomorphus geoffroyi.

Em 1942, com o rompimento das relações com a Alemanha e o ingresso do Brasil na Segunda Guerra mundial, por sua naturalidade alemã, Sick foi preso, primeiro na Ilha das Flores e depois na Ilha Grande. Continuou suas pesquisas no cárcere, observando o ecossistema local até ser liberto após dois anos de regime prisional. Em 1946 foi contratado como naturalista da Fundação Brasil Central, para a qual realizou expedições às regiões Centro-Oeste e Norte, narradas no livro Tukani ${ }^{1}$. Naturalizado brasileiro em 1952, foi o primeiro a escrever, de maneira mais aprofundada, sobre as aves brasileiras

\footnotetext{
${ }^{1}$ SICK, Helmut. Tukani. Unter Tieren und Indianern Zentralbrasiliens. Hamburgo: Paul Parey, 1957. Posteriormente traduzido para diversos outros idiomas. Em português, editado como Tukani: entre os animais e os índios do Brasil central. Marigo Comunicação Visual, 1997.
} 
ameaçadas de extinção. Trabalhou e colaborou com renomadas instituições, como o Max Planck Institut e a Washington State University. Sick também foi membro de diversas associações e sociedades científicas, como o Comitê Ornitológico Internacional e a Academia Brasileira de Ciências.

Durante toda sua vida planejou e integrou diversas expedições pelo país. Dentre elas está uma importante expedição realizada em dezembro de 1978 ao nordeste do Estado da Bahia, onde foi identificada a arara-azul-de-lear (Anodorhynchus leari), descoberta em 1823 e até então de localização desconhecida. De sua extensa e incansável produção, a mais importante obra de sua vida, o livro "Ornitologia Brasileira"2, publicado pela primeira vez em 1984, é uma importante referência bibliográfica até os dias atuais. A obra, de caráter pioneiro, é considerada o alicerce fundador do campo da ornitologia no Brasil. Durante cinquenta e dois anos de vida no Brasil, desde a chegada ao Estado do Espírito Santo, em 1939, até poucos dias antes de falecer, realizou intensa atividade científica. Sick faleceu na cidade do Rio de Janeiro no dia 5 de março de 1991.

Por ser viúvo e não deixar filhos, seus bens pessoais, assim como todos os documentos produzidos e acumulados durante a sua vida, foram deixados para o casal Kindel, também alemães e vizinhos de porta. Ingeburg Kindel, então viúva, após negociação, como legatária, doou o arquivo de Sick para Museu de Astronomia e Ciências Afins (MAST), instituto de pesquisa vinculado ao então Ministério da Ciência e Tecnologia. O MAST tem, dentre os seus objetivos, o de preservar, organizar e inventariar arquivos pessoais de cientistas para viabilizar o acesso a estudos e pesquisas relacionados à história da ciência. Embora a área de ornitologia não fosse área fim do Museu, este já possuía o Arquivo do Conselho de Fiscalização das Expedições Artísticas e Científicas no Brasil, o qual contém muitos documentos sobre as incursões de Sick em meio à Mata Atlântica para pesquisas. O Arquivo deste conselho foi nomeado no Projeto Memória do Mundo da Unesco, como reconhecimento de sua importância.

Os documentos do Arquivo de Sick foram acondicionados em 21 caixas do padrão do Arquivo de História da Ciência (AHC) do MAST, totalizando 2,73 metros lineares de documentos, entre textuais e iconográficos. Estes chegaram ao MAST sem acondicionamento adequado e não higienizados. A equipe do Arquivo de História da Ciência providenciou uma higienização superficial e acondicionamento provisório, com o objetivo de inseri-lo no depósito de guarda.

\section{Metodologia}

A tipologia documental compreende o estudo da identificação dos tipos de documentos de acordo com as atividades que os produziram, visando identificar a gênese documental, para melhor contextualizá-los. Constitui a etapa que antecede todo o tratamento arquivístico, pois é a partir da qual os documentos identificados serão classificados e descritos. Portanto, constitui-se a base para a organização do arquivo. Trata-se da análise da gênese do documento de arquivo, ou seja, dos motivos pelos

\footnotetext{
2 SICK, Helmut. Ornitologia Brasileira, uma introdução. Brasília: Editora Universidade de Brasília,
} 1985. 
quais o documento foi criado, com o objetivo de identificar a natureza da atividade e o objeto da ação, somado à espécie documental.

Desta maneira, a compreensão do contexto de produção e acumulação dos documentos se faz necessária, pois permite a identificação do produtor e dos tipos documentais que compõem o arquivo. Para identificar as espécies e tipos documentais do Arquivo Helmut Sick está em andamento o estudo de identificação da tipologia documental deste acervo. Para tanto, é imprescindível entender a biografia, história e trajetória pessoal do titular. A realização de uma pesquisa biográfica foi fundamental para a identificação das funções e atividades que o cientista desempenhou e para representá-las no futuro quadro de $\operatorname{arranjo}^{3}$ (ou classificação) do arquivo.

Os tipos documentais foram identificados a partir da suas características diplomáticas, com apoio do Glossário de Espécies e Tipos Documentais em Arquivos Pessoais do MAST (instrumento em fase de elaboração), e separados de acordo com as atividades desempenhadas pelo cientista. Esta separação inicial constitui uma proposta preliminar de quadro de arranjo, seguindo a metodologia do Arquivo de História das Ciências, como pode ser observado no Quadro 1:

Quadro 1- Quadro de Categorias de Atividades Pessoais e Profissionais de Cientistas

\footnotetext{
${ }^{3}$ Definido pelo Dicionário Brasileiro de Terminologia Arquivística como "Esquema estabelecido para o arranjo dos documentos de um arquivo, a partir do estudo das estruturas, funções ou atividades da entidade produtora e da análise do acervo. Expressão adotada em arquivos permanentes" (ARQUIVO NACIONAL, 2005).
} 


\begin{tabular}{|l|}
\hline \multicolumn{1}{|c|}{ 1. ATIVIDADES VINCULADAS À VIDA PESSOAL } \\
\hline 1.1 Documentos pessoais e de identificação \\
1.2 Relações familiares \\
\hline 1.3 Relações sociais \\
\hline 1.4 Assuntos financeiros \\
1.5 Atividades de lazer/entretenimento \\
\hline 1.6 Práticas religiosas \\
1.7 Educação \\
\hline \multicolumn{1}{|c|}{ 2. ATIVIDADES VINCULADAS À VIDA PROFISSIONAL } \\
\hline 2.1 Formação profissional \\
\hline 2.2 Atividades docentes \\
2.3 Atividades administrativas de unidades de pesquisa \\
2.4 Consultoria e assessoramento \\
\hline 2.5 Filiação em associações e entidades de classe \\
2.6 Gestão de políticas públicas para Ciência e Tecnologia \\
2.7 Intercâmbio de Informações Cientificas \\
\hline 3. ATIVIDADES DE PESQUISA EM CIÊNCIA E TECNOLOGIA \\
\hline 3.1 Administração da pesquisa \\
3.2 Desenvolvimento da pesquisa \\
\hline 3.3 Disseminação dos resultados da pesquisa \\
\hline \multicolumn{1}{|c|}{ 4. ATIVIDADES POLíTICAS } \\
\hline 4.1 Relações e atividades políticas \\
\hline 4.2 Atuação partidária \\
\hline
\end{tabular}

Fonte: Arquivo de História da Ciência (AHC) - MAST/MCTICT.

O Arquivo de Helmut Sick apresenta uma particularidade, que o diferencia dos demais arquivos de cientistas sob a guarda do Arquivo de História da Ciência: a grande maioria dos documentos trata de correspondência de Sick com outros pesquisadores e instituições científicas no Brasil e no exterior, especialmente Europa e Estados Unidos. O desafio consistiu na identificação das cartas, na tradução do conteúdo, e de seu contexto de produção, já que a atividade, pesquisa, trabalho ou ação que Sick desempenhava no momento da produção ou recebimento da carta, identifica a gênese do documento.

Contudo, nas cartas, nem sempre há, de forma clara, a fronteira entre o assunto principal (vinculada à atividade que promoveu a criação do documento) e outros assuntos diversos (SILVA, 2015). As cartas trocadas com outros cientistas e instituições científicas geralmente apresentam um objetivo específico sobre um tema em estudo, o que facilita identificar a ação que produziu. Para Goulart (2017, p. 54):

As cartas de classificação mais difícil são, sem dúvida, as mais informais, pela diversidade de funções, escritas por interlocutores próximos, dentre amigos e familiares. Há 
exemplares de relatos de experiências, impressões e sentimentos; (...). Comumente, elas tratam de tudo ao mesmo tempo, e elencamos para elas algumas denominações passíveis de classificá-las: cartas de amizade, de troca de experiências, de troca de ideias, de trocas intelectuais, diálogo epistolar ou, ainda, noticiário epistolar.

\section{5. $O$ arquivo pessoal de cientista como fonte de pesquisa}

Os arquivos pessoais de cientistas são formados pela produção e acumulação de documentos resultados das atividades da vida de seu produtor. Desta maneira, os anos de pesquisas estão registrados em arquivos pessoais de cientistas. Além disso, também podem ser encontrados registros de outros aspectos da vida do cientista, tornando os documentos presentes em tais arquivos de uma importância ímpar, pois, como já citado, documentam atividades que dificilmente seriam registradas por arquivos institucionais. Nesse sentido, a pesquisa em andamento busca identificar e organizar os documentos tendo como base o Quadro 1, com propostas de categorias de atividades. Compreendendo a identificação tipológica como mecanismo identificador da atividade produtora de um documento é possível levantar dados mais completos sobre o conjunto documentai, o contexto de produção e o modo de pensar a vida de seu titular.

No caso específico do Arquivo de Helmut Sick, o tratamento em curso já apresenta resultados preliminares. Quase noventa por cento dos documentos tratados até agora, as cartas, sendo as de intercâmbio de informação científica, são o tipo mais recorrentes. Este tipo documental foi assim nomeado pela equipe do projeto por se tratar de correspondência entre cientistas, ou entre cientista e instituições, com o objetivo de trocar informações a cerca das pesquisas desenvolvidas, incluindo até dados científicos. Estes documentos registram não apenas o diálogo e a troca de informações entre indivíduo-indivíduo, como também indivíduo-instituição. Em alguns casos é possível observar uma linha de desenvolvimento de uma pesquisa com o passar do tempo, através, por exemplo, do intercâmbio de informações por meio da troca de cartas entre Sick e cientistas.

Estes documentos constituem um rico material de pesquisa, pois, além de outras possibilidades, permitem acompanhar (de forma quase íntima) o desenvolvimento do pensamento científico, ou mesmo, da produção científica do produtor do arquivo, ou até, dos seus correspondentes. Além disso, até o momento, também identificamos anotações e desenhos estritamente relacionados com as pesquisas desenvolvidas por Helmut Sick que, a pensar de seu pioneiro protagonismo na ornitologia brasileira, podem constituir material de pesquisa e desenvolvimento deste campo do conhecimento no Brasil.

\section{Resultados parciais e considerações finais}

O trabalho de identificação documental demonstra-se um grande desafio. O gênero carta é um exemplo: a primeira vista parece um documento de fácil tipificação, porém como vimos, não o é. A julgar pela presença deste tipo documental no conjunto tratado até o momento (a lembrar, cerca de $90 \%$ ) é possível estimar a dimensão e complexidade que 
constitui a organização do Arquivo Helmut Sick. Soma-se a isso o fato de que a grande maioria dos documentos encontra-se em outros idiomas como inglês, francês e, sobretudo, alemão, a língua materna de Sick, que abarca grande parte da correspondência. Os documentos produzidos nesta última língua demandam mais tempo e cuidado em sua análise e identificação devido à soma da dificuldade causada pela falta de conhecimento do idioma alemão e à complexa atividade do estudo tipológico. Também foram identificados documentos manuscritos que oferecem um desafio a mais, uma vez que, além da barreira do idioma, requisitam conhecimentos avançados em paleografia.

A partir deste quadro, também foram identificados tipos documentais que atualmente não estão contemplados pelo Glossário de Espécies e Tipos Documentais em Arquivos Pessoais do MAST. Esses casos serão discutidos e avaliados ao final do tratamento, sendo submetidos, futuramente, à apreciação e validação da equipe do projeto, do Arquivo de História da Ciência e da consultora do projeto.

Os documentos presentes no Arquivo Helmut Sick representam a incansável produção e prática científica de um cientista apaixonado pelo seu ofício, sua pesquisa em busca de novos conhecimentos pela natureza e por sua preservação. Para Sick, o intercâmbio de informações científicas foi um importante fator de construção de conhecimento e de desenvolvimento científico, tanto para Sick, quanto para as instituições e pesquisadores com os quais se relacionou. A correspondência no arquivo de Sick se constitui em um valioso recurso que permite tanto o entendimento do contexto o qual pesquisador está situado, quanto do pensamento científico da época em que viveu e desenvolveu sua pesquisa. Através deste conjunto documental é possível remontar a construção e afirmação da ornitologia enquanto campo científico no Brasil, não apenas pelos métodos, práticas e outros aspectos da ciência, mas também pelos aspectos exclusivos da práxis ornitológica. O estudo do Arquivo de Helmut Sick permite a compreensão de um fazer científico e a reconstrução de sua história, promovendo a valorização da História da Ciência.

O trabalho de identificação de documentos realizado no Arquivo Helmut Sick revela a relação não somente de um pesquisador com a ciência e do fazer científico, mas também a relação entre indivíduo e sociedade. É possível perceber, mesmo que de forma preliminar, que a organização do acervo proporcionará uma valiosa fonte de pesquisa histórica, arquivística e científica.

\section{Referências}

ARQUIVO NACIONAL (Brasil). Dicionário brasileiro de terminologia arquivística. Rio de Janeiro: Arquivo Nacional, 2005. 232p.

BELlOTTO, H. L.Como fazer análise diplomática e análise tipológica de documento de arquivo. São Paulo: Associação de Arquivistas de São Paulo / Arquivo do Estado, 2002 (Projeto Como Fazer, 8).

CAMARGO, A. M. de A. Contribuições para uma abordagem diplomática dos arquivos pessoais. Estudos Históricos, Rio de Janeiro, v.11, n. 21, p.169-174, 1998. 
CAMARGO, Ana M. A.; GOULART, Silvana. Da teoria à prática: tempo e circunstância: a abordagem contextual dos arquivos pessoais. São Paulo: Instituto Fernando Henrique Cardoso, 2007.

GOULART, S.. O tratamento da correspondência em arquivos pessoais: desafios e controvérsias. CAMPOS, J F. G. (Org.). Arquivos pessoais: experiências, reflexões, perspectivas [recurso eletrônico]. São Paulo, Associação dos Arquivistas de são Paulo, 2017. p. 38-50.

SANTOS, P. R. El. dos. Arquivo pessoal, ciência e saúde pública: o arquivo Rostan Soares entre o laboratório, o campo e o gabinete. In: SILVA, M. C. S. de M. e; SANTOS, P. R. E. dos. Arquivos pessoais: história, preservação e memória da ciência. Rio de Janeiro : Associação dos Arquivistas Brasileiros/FAPERJ, 2012. p. 21-50.

SILVA, M. C. S. de M. Os Arquivos Pessoais como Fonte: reconhecendo os tipos documentais. In: GRANATO, M. (org.). MAST: 30 ANOS DE PESQUISA. Rio de Janeiro: Museu de Astronomia e Ciências Afins, v. 1, p.177-203. 2015.

.Configuração e recuperação da informação em documentos de ciência e tecnologia: estudo tipológico no arquivo pessoal do físico Bernhard Gross. Perspectivas em Ciência da Informação, v. 18, n. 3, p. 160-174, jul./set. 2013a.

SILVA, M. C. S; de M. ; SANTOS, P. R. E. dos. Arquivos pessoais: história, preservação e memória da ciência. Rio de Janeiro: Associação dos Arquivistas Brasileiros/FAPERJ, 2012. 192p.

SILVA, M. C. S. de M. ; TRANCOSO, M. C. D. Produção documental de cientistas e a história da ciência: estudo tipológico em arquivos pessoais. História, Ciências, SaúdeManguinhos (Online), v. 22, n. 3, p. 849-861, 2015. 